\section{THE POOR-LAW MEDICAL SERVICE: COMING LEGISLATION.}

By William Holder, M.R.C.S. Eng., J.P.,

MEDICAL OFFICER AND PUBLIC VACCINATOR FOR THF SUTTON DISTRICT OF THE SCULCOATES UNION; LATE SURGEON TO THE HULL AND SCULCOATES DISPENSARY.

THE speeches in the House of Lords on the recent Reports of the Poor-law Commission mark "footprints on the sands of time." The head of the State Church, the Archbishop of Canterbury, was roused to press that the conclusions of the Commissioners should not be disregarded or delayed; and the leader of the Government in that House, Lord Crewe, said significantly: "The system [Poor-law Act Regulations] of 1834 had reached its limits, and if there was to be any real improvement we must look to something else," and followed his words by the declaration that "this was a vast subject, but not too vast to be dealt with within the immediate future." This is all the evidence we need that vast changes affecting the medical profession are imminent. It therefore behoves the profession, as a trusted body of the State, to interest itself in the matter, to study the subject, to determine its policy, and to advise the State on matters in which nearly 4000 medical men are personally concerned, and about which they have the most intimate knowledge. The members of the medical profession as a general body may then be asked to act as faithful allies to their colleagues of the Poor-law Medical Service and to give active support to any well-considered scheme that may be forthcoming to put the Poor-law Medical Service in a more efficient position.

The two reports of the Poor-law Commissioners are very searching. Some member or members of that Commission must have had practical knowledge of the difficulties and deficiencies under which Poor-law medical officers conduct their efforts and must have effectively impressed the signatories of both the Majority and Minority Reports with the gravity of the position and the needs for recognition and help of the medical part of Poor-law management. Whoever took this line, let us not forget to be grateful.

On all hands the importance of these two reports is granted, and this by no class more freely than by the many boards of guardians who have, on the whole, humanely-so far as their knowledge went--carried out the system of the 1834 Act. These boards have, at any rate in some of our larger cities, endeavoured to meet, by extended help to the poor, the developments which increased wealth and wider intelligence have given to the country. In the treatment of the sick, unfortunately, many boards have made no movement, but since these reports have been published numerous guardians have read them and baving enlightened themselves are showing a willingness to profit by the lessons. Certain boards of guardians have submitted questions to their medical officers asking for information and for suggestions as to the management of medical matters and the regulations of areas-a thing never done before. As all amendments of a law must be founded on experience of defects in its working, it may not be unhelpful to lay before the profession a series of queries put by one board of guardians to the district medical officer, and the replies of that officer who has had charge for over a quarter of a century of one of the largest districts in one of our great cities.

\section{Letter from the District Medical Officer of Medical Relief District No. — of the — Union to the Clerk of the B-Bard of Guardians. \\ Medical Retief District No. -}

[The letter commences by the medical officer explaining that it has been his duty as a member of the Council of the Poor-law Medical Officers Association, not only to read the Reports of the Royal Com mission, but to attend a National Conference of the Poor-law Medical Officers Association at which Commissioners who signed both Reports read papers expounding the medical aspect of their respective views, and also to read the memorandum of the chief medical district inspector of the Local Government Board. He has thus learnt something of the tendency of the legislation which is coming. But if the Commissioners, after five years of industrious endeavour, admit their conclusions are incomplete, it cannot, he submits, be expected that within the limits allowed he can cover the complex medical problems which are involved in the questions. He continues :-

The most prominent trend of change in the District Medical Service is to bring the district medical officer's work into relationship with that of the sanitary medical system of the locality in which he acts. The management of poverty and its disease causes is so blended that the separation of the district medical officers from the control of the gurrdians is unlikely; but a practical defect is felt--viz,, that district medical officers see insanitary causes, such as filthy homes, defective privies, blocked and broken sinks, verminous dirty persons, slovenly dirty mothers, in untended houses in which are children with suppurating eyes, and even contaminating diseases, such as chicken-pox and other Important causes, inviting, originating, and continuing disease; and yet though seen and deplored by district medical officers as a cause of poverty, they (the district medical officers) are out of the machinery which removes them. They have no duty to report them to the sanitary authority.

This evidences want of some official link between two departments doing related yet now separated work. There should be some connexion between these two offices in the interest of the ratepayers as well as the poor themselves.

$I$ answer the detailed questions :-

QUERY 1.-So far as your district is concerned, do you think that the present boundaries and arrangements are conducive to a satisfactory administration of relief to the sick poor?

ANSWER 1.- The arrangements are not conducive to a satisfactory on of relief to the sick poor.

(a) The sanitary services are too related in work to be separated in action.

(b) When a severe epidemic arises some automatic method of supernumerary temporary assistance should be provided; and as the district medical officer is the first in the field to note an epidemic originating and advancing, and the best qualified judge of its causes and its virulence, he should be officially authorised to send his valuable information to the sanitary authority, otherwise the sanitary authority can only generally be informed of a coming epidemic by an advancing death-rate or defective school attendance.

(c) The closing entirely of the relief office for so long a period as from saturday noon to Monday morning is a defect to be remedied. I am making no reflection on relieving officers. They are kindness and consideration itself to the poor, and in this Saturday to Monday interregnum, when they are found, they readily sacrifice their leisure to meeting all necessities; but many cases occur when poor persons do not know where to get orders for medical attendance. The district medical officers, if they hear of the case, attend without an order, but the poor have some difficulty in understanding this.

(d) "Not on the book" orders should be recognised and paid for as extra medical work. There is no doubt much suffering caused to honest poor persons, temporarily down on their luck, unable to pay reasonable charges for efficient medical attendance, who are not entitled to be in receipt of parish relief, and who are unable to obtain infirmary or dispensary orders. These people might fairly have medical aid much extended to them, not at the cost of the medical attendant, but at the expense of the rates or the State.

(e) A very desirable new "arrangement" would be that a supply of binders, pins, and a few napkins should be kept and by certificate given out by the relieving officers to those needing them, as accouchement necessities. It
is not unusual for a district medical officer to have to is not unusual for a district medical officer to have to
attend midwifery cases in houses where not even a clean attend midwifery
rag is to be found.

(f) During the absence of the district medical officer on his yearly holiday no substitute is provided.

In answer to that part of the question relating to "present boundaries" I would say that:-

(i) My present boundary is workable, but some automatic supernumerary help ought to be provided to the district medical officer when the outer fringe of his district, if bordering on open lands, has its population greatly increased.

(ii) In fixing the remuneration for each boundary the poverty of a district should bear reasonable relationship to the number of its likely sick poor.

QUERY 2.-Is the present arrangement for the supply of medicines, dressings, \&c., satisfactory in the interests of the patients and dressings, \&c., satisfactory in the interests of the patients and
suitable to their necessities? Would you advocate the establishment of district dispensaries, to be maintained by the guardians, ment of district dispensaries, to be maintained by the guardians, where sick paupers could be supplied with medicines, \&c.,
the written recommendation of the district medical officers :

ANSWER 2. - The present arrangement for the supply of medicines, dressings, \&c. is not satisfactory in the interests of the patients or suitable for their necessities or cure. The modern aseptic dressings, antiseptics, gauzes, \&c.; the modern medicines. dressings, antiseptics, gauzes, ac.; the modern medicines; the serums, liquid animal extracts, new chemical synthetical compounds, and other modern expensive helps, which shorten many illnesses, are a serious cost, one prohibitive to the district
medical officer. This unreasonable charge on the doctor invites medical officer. This unreasonable charge on the doctor invites neglect or dulls his perception of the extensive and proper
use of new remedies. It is but natural, he feels, that the use of new remedies. It is but natural, he feels, that the
guardians should pay him at least the average of what the average patient costs in medicines and appliances in the house if they wish him to treat his eases according to modern methods. I have tried to keep my conscience clear and to forget my pecuniary penalty for doing right, but I must say of absorbent lint with iodoform gauze, bandages, and dressings for one patient who had an old ulcer of the leg. or to send 48. 6d. to London for some thyroid elixir, because it must be fresh extracted to be potent, I felt that I was paying out of my pocket, and unju

The foregoing are reasons why the establishment of district dispensaries for the dispensing of drugs and appliances, found and paid for by the guardians, is necessary. I would, however, places only and not outdoor departments, that is, dispensing and consulting establishments combined, for is, dispensing ailing, weakly, malodorous, expectorating hordes are huddled ship for consultations, later to be huddled into companion- 
to wait a further long period for medicines to be dispensed. Definite consultation hours at the surgery of the district medical officer is a much better arrangement. The medical officer is to be found there; he gives two hours daily at his house, 9 to 10 in the morning, and 5 to 6 in the evening, for consultations, taking messages, and giving certificates. At the the surgeries of the district medical officers are better separated than at the dispensaries, and after seeing the medical officer they would walk a little way to the dispensaries-which should be central to the districts concerned-and there get their medicines from a dispenser. At the surgeries of district medical officers patients are less huddled together. The doctor can give them more time and attention and keep better continuity with the case, and, what is more important, in emergency the sick quickly get at him at any hour of the day or night at his known quickly get at him at any hour of the day or night at his known
residence. There is no need to wait until the dispensary opens residence. There is no need to
again to communicate with him.

QUERY 3.-Can you suggest any improvement in respect of the subject-matter of Query No. 1 or Query No. 2? If so please state fully in what direction.

ANSWER 3.- My suggestions are as given above.

QUERY 4.-Do you consider the clerical work attached to your office is unnecessarily extensive? Do you carry out fully the requirements of the Orders and regulations of the Local

(a) Sending of notices to local health authority in case of
(a) contagious, infectious, or epidemic diseases. (A.O., February 12th, 1879.)

(b) Keeping of the "District Medical Officer's Relief Book." (A.O., February 26th, 1866.)

(c) Giving of certificates specifying the ailments of paupers attended by you, when requested by the relieving
officers or the paupers themselves. (G.O., July 24th, 1847$.

ANSWER 4.-Undoubtedly some clerical record of our work is neces sary, but some of the present records are unnecessary, irksome, had over 30 years' experience of parochial and parish district and hospital work in many counties in England. I never knew a parish medical register properly kept. It is known that hence the doctor feels bis time is too important to be wasted, and thinks it is not necessary to fill in every visit or bottle of and thinks it is not necessary to fill in every visit or bottle of
medicine. He feels that a record of visits, of medicine given, or medicine. He feels that a recordjof visits, of medicine given, or of surgery attendance generally is sufficient if it shows reliable it might have been necessary to use red instead of black ink to distinguish between his work and the principal's, but in these tinguish between his work and the principal's, but in these
days, when all visiting assistants and partners must be fully days, when all visiting assistants and partners must be fulty
qualified, and have to be accepted as deputies, it is needless.

I strictly attend to $(a)$ so far as the Infectious Diseases Notification Act requires; I attend to (b) except that my dispenser copies from my daily visiting book and keeps the record of medicines dispensed; and (c) Yes.

QUERY 5.-Any general observations, remarks, or suggestions as to the treatment of the sick poor would be appreciated.

ANSWER 5.-It is only fair that the district medical officer should be paid by salary for his professional services, and not have to find drugs and appliances. It is better he should be a part time officer in general practice - a doctor of standing and experience in the district-that is, if he is to have influence with the ence in the district-that is, if he is to have infuence with the
dirty and improvident. The knowledge of the usefulness and influence of the district medical officer over the poor is much influence of the district medical officer over the poor is much
misunderstood. His work is as often to stay poverty as it is to misunderstood. His work is as often to stay poverty as it is to
cure disease. Poor patients do accept advice from the doctor they would refuse from others; they look on him as their friend, confidant, and adviser. He understands their misfortunes as well as their ills, and their weaknesses of temperament, which form the key of many of their improvident deficiencies. They trust him because he is by training no super-
cilious puritan in judging them. This reliance on the doctor and cilious puritan in judging them. This reliance on the doctor and his disinterested advice could be used to the greatest amelioration of poverty and sickness. He might be made what the State has a "pervading influence." His education and professional skili gain the respect, I had nearly said reverence, of bis poor, and should demand that he be recognised as a man worthy of proper reward. His work does not begin at 9 A.M. and end at 5 P.M., as ordinary workers, with half Saturday and Sunday for rest. His duties begin at 9 A.M. on Monday morning and continue night and day to the following Monday. He has no yearly holiday allowed. This injustice has never been squarely faced by guardians. Services begun by the profession, as benevolent labour of the profession has been accepted without scruple. I respectfully hope the guardians will not allow this to continue now that, without the interference of the patient distric medical officers, the inquiries of the Commission have called out against this abuse.

he salary should be adequate and not stinting. The work is heavy, exacting, and noble. Properly recognised, it is certain the service will see removed the reproach, "he is only the parish doctor." This is never uttered by the poor they serve, but by doctor." This is never uttered by the poor they serve, but by the richer people who do not see his work or sacrifices in a field attendants do for the medical man.

It must never be forgotten that medical skill is, and will ever be, diagnostic, and not mechanical or stereotyped. Cases cannot be treated wholesale; each case requires original research and the key to short illness, and proper treatment by food medicine, and sanitation shortens the period of parish relief in acute cases and prevents its recurrence.

In the Poor-law Commissioners' reports the suggestion of blending parish patients with contributory patients in a part-charity supported institution will do harm. The suggestion is the outcome of the London system of contract practice, and of club
practice in the provinces, both practices un worthy the profession and the patients. If such are established they will increase the area of pauperism, degrade those who can pay, and stup the flow of benevolence.

I venture to suggest much more generous doles to respectable aged widows and men, especially valetudinarians. The most helpful thing would be the building of self-contained twostorey houses with open gardens, such as I have seen in Holland. Then, after classification, two or three persons of the same sex could be placed rent free in one of these domiciles or fiats. The combined allowances of three persons would be spent more economically. For instance : one fire, one pie, one boiling of potatoes, one light; and many other things might be enumerated where one would serve three persons collectively better than three single persons in three rooms. Another advantage than three single persons in three rooms. Another advantage panionship and show compassion one to the other in the passing panionship and show compassion one to the other in the passing sicknesses of age. They would give ordinary nursing to each the buildings could be made into wards for more serious cases, requiring more serious nursing. If this was not more econorequiring more serious nursing. If this was not more econofeels because the stinted allowance given to respectable out-door feels because the stinted allowance given to respectable out-door aged men and women paupers is in

More power is needed to get cleanliness in some houses and from some parish patients. Slatternly homes beget slatternly children, and they become slatternly mothers of future slatterns. Whilst seeing failure in dragooning the indolent into cleanliness, a system of loans of cleaning materials and of payment for scrubbing and whitewashing I am sure would have a two-fold effect. It would make the recipients of the loans feel they were earn

The present method of mending disease and leaving the originating causes to act again is indefensible. The Poor-law medical officer as a sanitary adviser could get much carried out better than other officers. If tactfully managed the poor would accept advice from the doctor better than from any other person.

I would like to say how impressed I am with the good effected in placing out nurse children with aged women. I know several instances where the foster boys have been all a son should be to an aged mother and where the woman has lavished her solicitude on the children's morals and worldly improvement with the greatest success. In fact I have never known but one failure to get the greatest benefit and blessing to child and foster-parent in these cases.

May I lastly appeal to the guardians to increase the fee for attendance on parish patients at accouchements. It is not fair or reasonable to pay a fee below that paid to the midwife. The task is not the ordinary attendance. The work is done with often little light. The patient has few clothes and no cleanliness. The doctor sits hour by hour through the silent watches of night, saving life and helping the weak and suffering, and may demand a reasonable reward. District visiting nurses. should be provided for accouchement cases. Such nurses should be exclusively used for labour cases. They should not be employed in dressing wounds or ulcers or in surgical cases. They should act solely under the direction of the doctor in charge. It may be accepted as a fact that these nurses have a greater influence on the habits of the poor than is supposed. and their influ helpless how much nays reaches far outside their passing visit and example.

Finally, the fees for extra surgical work require readjusting.

$I$ have written fully because I feel legislation is coming on some of these lines.

Neither the questions of the Board of Guardians nor my answers, which in this publication of them have received a certain amount of emendation, cover the whole subject, but they mention many practical points and suggest some remedies. I submit them as a contribution to the complete discussion of the subject to which the columns of THE LANCET are clearly open, and with the idea that they may stimulate others who are directly interested towards some prompt and common course of action.

Opening of QueEn Alexandra Sanatorium, Davos. - The British sanatorium in the Alps, for the successful completion of which the unceasing labour of the local secretary, Mr. H. C. Wrinch, has mainly to be thanked, will be open for the reception of patients at the end of this month, although the inaugural ceremony is to be postponed until the winter season. On the visiting staff are Dr. W. R. Huggard, H.B.M. Consul in Davos, Dr. Arnold F. Bill, and Mr. Florian Buol; and the resident staff consists of Dr. Joseph W. Noble as medical superintendent, and Dr. James Fairley as junior resident medical officer. The matron, Mrs. Teesdale, who for some years past had the entire management of the Davos Invalids ${ }^{3}$ Home, will be assisted by a small staff of English nurses with home sanatorium training. Although each patient occupies a separate room, the inclusive charge is only to be $38 s$. per week. Only early or convalescent cases are eligible. A large number of applications having already come in, candidates should not delay obtaining forms from the local secretary in Davos, Mr. H. C. Wrinch, or from the honorary secretaries in London, Dr. William Ewart, 31, Upper Brookstreet, W., and Mr. D. A. F. Vesey, 3, Camp View, Wimbledon Common, S.W. 